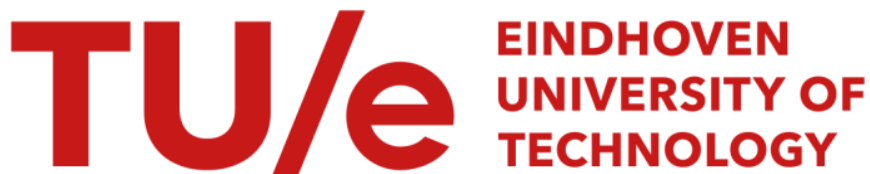

\section{Subcycling applied to ordinary differential equations}

\section{Citation for published version (APA):}

Bruijs, W. E. M., Florie, C. J. L., Coo, de, P. J. A., \& Sauren, A. A. H. J. (1991). Subcycling applied to ordinary differential equations. In Real-time integration methods for mechanical system simulation : proceedings of the NATO Advanced Research Workshop on real-time integration for mechanical system simulation, August 7-11, 1989, Snowbird, Utah, USA / Ed. E.J. Haug, R.C. Deyo (pp. 249-262). (NATO ASI series. Series F; Vol. 69). Springer.

Document status and date:

Published: 01/01/1991

\section{Document Version:}

Publisher's PDF, also known as Version of Record (includes final page, issue and volume numbers)

\section{Please check the document version of this publication:}

- A submitted manuscript is the version of the article upon submission and before peer-review. There can be important differences between the submitted version and the official published version of record. People interested in the research are advised to contact the author for the final version of the publication, or visit the $\mathrm{DOI}$ to the publisher's website.

- The final author version and the galley proof are versions of the publication after peer review.

- The final published version features the final layout of the paper including the volume, issue and page numbers.

Link to publication

\section{General rights}

Copyright and moral rights for the publications made accessible in the public portal are retained by the authors and/or other copyright owners and it is a condition of accessing publications that users recognise and abide by the legal requirements associated with these rights.

- Users may download and print one copy of any publication from the public portal for the purpose of private study or research.

- You may not further distribute the material or use it for any profit-making activity or commercial gain

- You may freely distribute the URL identifying the publication in the public portal.

If the publication is distributed under the terms of Article $25 f a$ of the Dutch Copyright Act, indicated by the "Taverne" license above, please follow below link for the End User Agreement:

www.tue.nl/taverne

Take down policy

If you believe that this document breaches copyright please contact us at:

openaccess@tue.nl

providing details and we will investigate your claim. 


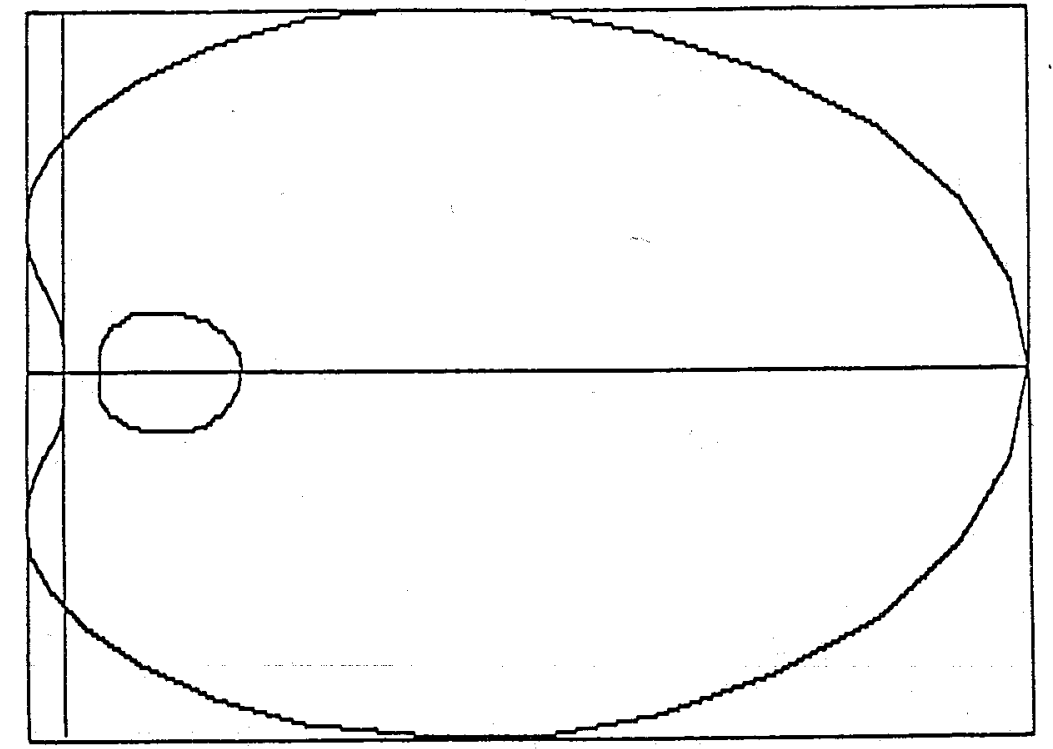

Figure 1. Stability Region for $k=3$.

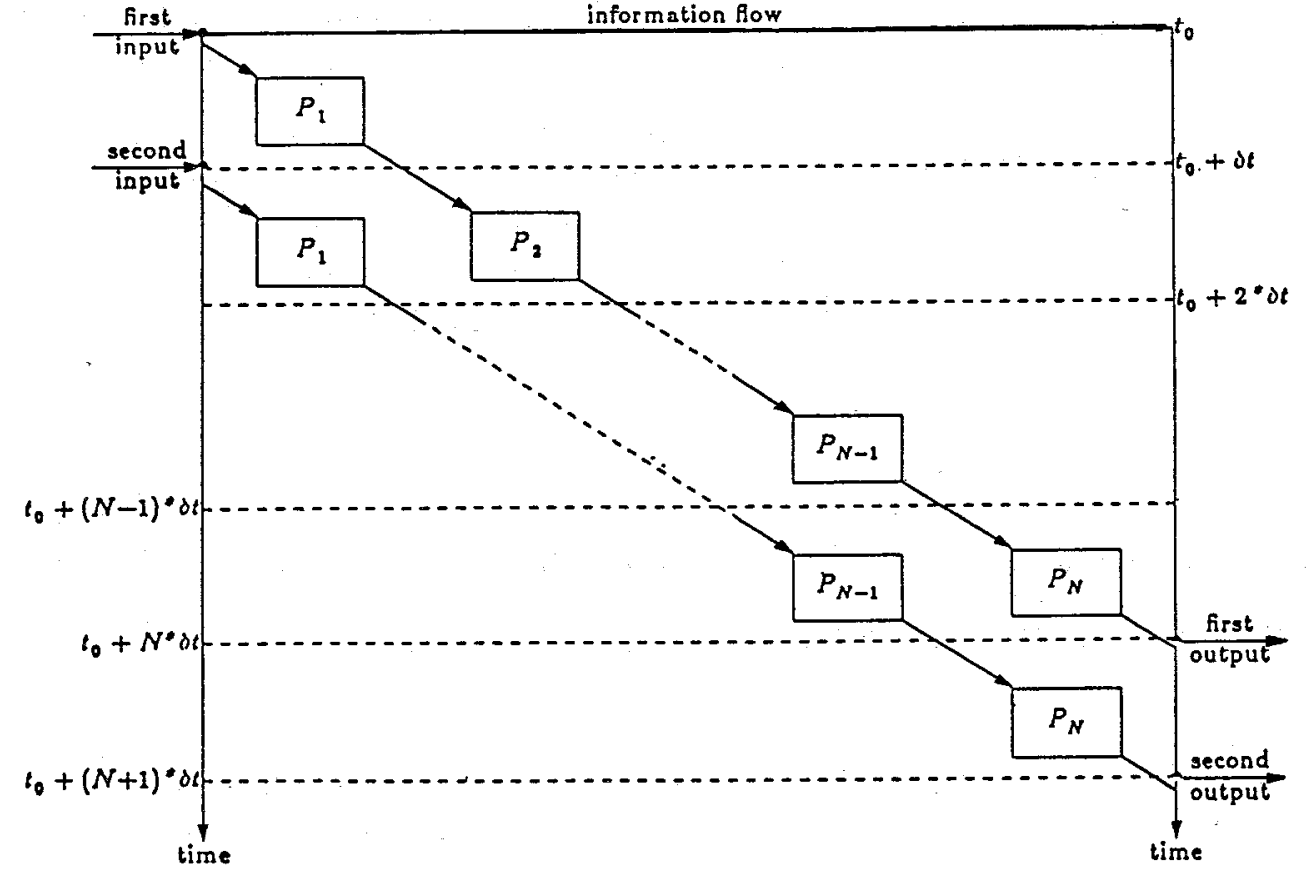

Figure 2. Delay in Real-time Parallelism.

\section{SUBCYCLING APPLIED TO ORDINARY DIFFERENTIAL EQUATIONS}

W.E.M. Bruijs ${ }^{*}$, C.J.L. Florie ${ }^{* *}$, P.J.A. de Coo ${ }^{* * *}$, A.A.H.J. Sauren ${ }^{*}$

* Eindhoven University of Technology

Faculty of Mechanical Engineering

P.O. Box 513

$5600 \mathrm{MB}$ Eindhoven

The Netherlands

\section{ABSTRACT}

An important application of explicit integration methods is to find the solution of a set of ordinary differential equations which is obtained using the finite element method. In many engineering applications, the finite element mesh consists of areas where large deformations are expected and areas where only small deformations are expected. In the areas where large deformations are expected, a fine mesh is necessary, while in the other areas a coarse grid is sufficient. The Courant criterion states that the time step must be smaller than the characteristic length of the element divided by the dilatational wave speed. Due to this Courant criterion, in the fine grid a small time step is necessary to ensure a stable solution. In the coarse grid, a much larger time step is allowed for the integration. If subcycling is applied, different time steps are allowed in the same mesh. This means that the smaller elements can be integrated with smaller time steps than the larger elements. This will lead to a decrease of the number of element calculations and hence to a decrease of the computer time.

$$
\begin{gathered}
\text { ** PISCES International bv } \\
\text { Groningenweg } 6 \\
\text { 2803 PV Gouda } \\
\text { The Netherlands } \\
\text { *** TNO Road-Vehicles Research Institute } \\
\text { P.O. Box 237 } \\
\text { 2600 AE Delft } \\
\text { The Netherlands }
\end{gathered}
$$


In this paper, the subcycling algorithm is presented. A case study is used to derive the stability of the algorithm. An algorithm which automatically divides a finite element mesh into groups of elements that are treated with different time steps will be discussed. This algorithm chooses the group division in such a way that the simulation costs are minimal. The subcycling method will be applied to some test cases. The results of these test cases will be presented. It will be shown for the test cases that application of subcycling yields substantial computer time savings. The loss of accuracy due to the application of subcycling is acceptable for many engineering applications.

\section{INTRODUCTION}

Basically two different methods for the numerical integration of a set of ordinary differential equations (ODE's) can be distinguished: implicit and explicit methods. If the set of ODE's is obtained after spatial discretization of a structure with the finite element method, the mass matrix can be lumped (Krieg \& Key, 1973), resulting in a diagonal mass matrix. If the mass matrix is diagonal, the application of an explicit method implies that no sets of equations have to be solved during a time step, so the calculations are very efficient. In exchange for this, explicit methods are only conditionally stable. The time step used for the integration is bounded by the Courant criterion (Courant, Friedriechs \& Lewy, 1928), which states that the time step must be smaller than a characteristic length of the element divided by the dilatational wave speed in the material. An advantage of implicit methods is that they often are unconditionally stable. This implies that the time step is not bounded by stability considerations, but can be chosen based on accuracy demands only. The disadvantage of implicit methods is the necessity to solve a set of equations during each cycle. Computational costs and core storage for the solution of a set of equations increase dramatically for larger numbers of degrees of freedom.

It depends on the characteristics of the set of ODE's that must be solved which integration method is most suited. However, in many engineering applications, none of the methods by itself is very efficient. For example, if a crash simulation of a vehicle structure is performed, the number of degrees of freedom is huge. So the application of an implicit method is not very efficient for this problem. On the other hand, the large deformations that are to be expected in some parts of the vehicle structure require some very small elements in that area. This means that, due to stability conditions, a very small time step must be applied, if an explicit method is used. Explicit methods are thus not particularly efficient for this problem as well.

In this paper, a method is described that allows different time steps for the solution of a set of coupled ODE's. This technique - often called subcycling - is applied in combination with an explicit integration scheme, the central difference method. Each equation of the set of ODE's is integrated with a time step that is close to the maximum stable time step for that equation. For the example of the crash simulation of the vehicle structure, this implies that the smaller elements will be treated with a smaller time step than the larger elements. So for the larger elements, the number of calculations per element will decrease and thus the computer time will decrease.

\section{SUBCYCLING}

Consider a set of ODE's resulting from spatial discretization of a structure with the finite element method:

$$
\underline{M \ddot{x}}=f_{\text {ext }}(t)-f_{\text {int }}(t, \underline{x})
$$

where $\underline{\mathrm{M}}$ is the lumped mass matrix, $\ddot{\underline{x}}$ the column containing the nodal accelerations, $\mathrm{f}_{\text {ext }}$ the column containing the nodal external forces that are a function of time $t$, and $f_{\text {int }}$ the column containing the internal nodal forces that are a function of the column containing the nodal displacements $\underline{x}$ and time $t$.

Equation (1) can be integrated with the central difference method:

$$
\begin{aligned}
& \underline{\dot{x}}_{n+1 / 2}=\underline{\dot{x}}_{n-1 / 2}+\Delta t \underline{\underline{x}}_{n} \\
& \underline{x}_{n+1}=\underline{x}_{n}+\Delta t \underline{x}_{n+1 / 2}
\end{aligned}
$$

*) In this paper, an underlined upper case symbol denotes a matrix and an underlined ** lower case symbol a column. A superposed dot stands for the time derivative. ) A subscript denotes that the quantity is considered at a certain point of time, e.g. $\underline{x}_{n+1}$ denotes the column of the nodal displacements at time $(n+1) \Delta t$. 
If (1) is considered at time $\mathrm{n} \Delta \mathrm{t}$, the accelerations can be calculated at this time:

$$
\underline{\ddot{x}}=\underline{\underline{M}}^{-1}\left[\mathrm{f}_{\text {ext }}\left(\mathrm{t}_{\mathrm{n}}\right)-\mathrm{f}_{\mathrm{int}}\left(\mathrm{t}_{\mathrm{n}}, \underline{\mathrm{x}}_{\mathrm{n}}\right)\right]
$$

It is assumed that the mass matrix is lumped, so the inversion of $\underline{M}$ is trivial due to the diagonal form of $\underline{\mathrm{M}}$. Substitution of $\underline{\underline{x}}_{\mathrm{n}}$ in (2) yields $\underline{\underline{x}}_{\mathrm{n}+1 / 2}$ and substitution of the latter in (3) yields $x_{n+1}$.

Because of the conditional stability, the time step used for the integration must satisfy (Courant, Friedriechs \& Lewy, 1928):

$$
\Delta \mathrm{t}<\mathrm{d} / \mathrm{c}
$$

where $d$ is a characteristic length of an element and $c$ is the dilatational wave speed, which is dependent on the material parameters.

When subcycling is used, the ODE's are integrated with different time steps. For reasons of simplicity, the case for which only two different time steps are used for the integration, is considered. The set of ODE's will be split up into two partitions, denoted by the superscripts a and b.:

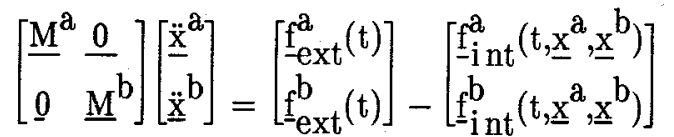

Eq. (6) can be regarded as two coupled sets of ODE's. Partition a will be integrated with time step $\alpha \Delta \mathrm{t}$ and partition b with time step $\Delta \mathrm{t}$. The parameter $\alpha$ is the ratio between the time steps and must be a positive integer number. A calculation with a time step $\alpha \Delta t$ is called a cycle, an update with the time step $\Delta t$ is called a subcycle. During a cycle the following computations have to be performed:

- Updates for partition a:

$$
\underline{\ddot{x}}_{n}^{a}=\underline{M}^{a^{-1}}\left[\underline{f}_{e x t}^{a}\left(t_{n}\right)-\underline{f}_{i n t}^{a}\left(t_{n}, \underline{x}_{n}^{a}, \underline{x}_{n}^{b}\right)\right]
$$

$$
\begin{aligned}
& \underline{\dot{x}}_{\mathrm{n}+\alpha / 2}^{\mathrm{a}}=\underline{\dot{\mathrm{x}}}_{\mathrm{n}-\alpha / 2}^{\mathrm{a}}+\alpha \Delta \mathrm{t} \underline{\underline{x}}_{\mathrm{n}}^{\mathrm{a}} \\
& \underline{\mathrm{x}}_{\mathrm{n}+\alpha}^{\mathrm{a}}=\underline{\mathrm{x}}_{\mathrm{n}}^{\mathrm{a}}+\alpha \Delta \mathrm{t} \dot{\underline{x}}_{\mathrm{n}+\alpha / 2}^{\mathrm{a}}
\end{aligned}
$$

- Updates for partition $b$

$$
\begin{aligned}
& \underline{\ddot{x}}_{n}^{\mathrm{b}}=\underline{\underline{M}}^{\mathrm{b}}{ }^{-1}\left[\underline{\mathrm{e}}_{\mathrm{ext}}^{\mathrm{b}}\left(\mathrm{t}_{\mathrm{n}}\right)-\underline{\mathrm{f}}_{\mathrm{int}}^{\mathrm{b}}\left(\mathrm{t}_{\mathrm{n}}, \underline{\mathrm{x}}_{\mathrm{n}}^{\mathrm{a}}, \underline{\mathrm{x}}_{\mathrm{n}}^{\mathrm{b}}\right)\right] \\
& \dot{\underline{x}}_{n+1 / 2}^{b}=\underline{\dot{x}}_{n-1 / 2}^{b}+\Delta t \underline{\underline{x}}_{n}^{b} \\
& \underline{x}_{n+1}^{b}=\underline{x}_{n}^{b}+\Delta t \dot{x}_{n+1 / 2}^{b} \\
& \underline{\ddot{x}}_{n+1}^{b}=\underline{M}^{b^{-1}}\left[\underline{f}_{e x t}^{b}\left(t_{n+1}^{b}\right)-\underline{f}_{i n t}^{b}\left(t_{n+1}, \underline{x}_{n+1}^{a}, \underline{x}_{n+1}^{b}\right)\right] \\
& \dot{\underline{x}}_{n+3 / 2}^{b}=\dot{\underline{x}}_{n+1 / 2}^{b}+\Delta t \underline{\ddot{x}}_{n+1}^{b} \\
& \underline{x}_{n+2}^{b}=\underline{x}_{n+1}^{b}+\Delta t \underline{\dot{x}}_{n+3 / 2}^{b}
\end{aligned}
$$

upto:

$$
\begin{aligned}
& \ddot{\underline{x}}_{\mathrm{n}+\alpha-1}^{\mathrm{b}}=\underline{\mathrm{M}}^{\mathrm{b}^{-1}}\left[\underline{\mathrm{f}}_{\operatorname{ext}}^{\mathrm{b}}\left(\mathrm{t}_{\mathrm{n}+\alpha-1}\right)-\underline{\mathrm{f}}_{\mathrm{int}}^{\mathrm{b}}\left(\mathrm{t}_{\mathrm{n}+\alpha-1}, \underline{\mathrm{x}}_{\mathrm{n}+\alpha-1}^{\mathrm{a}}, \underline{\mathrm{x}}_{\mathrm{n}+\alpha-1}^{\mathrm{b}}\right)\right] \\
& \dot{\mathrm{x}}_{\mathrm{n}+\alpha-1 / 2}^{\mathrm{b}}=\dot{\mathrm{x}}_{\mathrm{n}+\alpha-3 / 2}^{\mathrm{b}}+\Delta \mathrm{t} \underline{\underline{x}}_{\mathrm{n}+\alpha-1}^{\mathrm{b}} \\
& \underline{\mathrm{x}}_{\mathrm{n}+\alpha}^{\mathrm{b}}=\underline{\mathrm{x}}_{\mathrm{n}+\alpha-1}^{\mathrm{b}}+\Delta \mathrm{t} \underline{\mathrm{x}}_{\mathrm{n}+\alpha-1 / 2}^{\mathrm{b}}
\end{aligned}
$$

For partition a, the displacements are only known at times $0, \alpha \Delta t, 2 \alpha \Delta \mathrm{t}$, etc. But for the calculation of the accelerations of partition $b$ at intermediate points of time, the displacements of partition a must be known at these intermediate points of time. This is due to the fact that $\underline{f}_{i n t}^{b}$ is not a function of $\underline{x}^{b}$ only, but also depends on $\underline{x}^{\mathrm{a}}$. In Bruijs, et al. (1988), different methods to find an approximation of the intermediate values of $\underline{x}^{2}$ 
are compared with respect to numerical stability, accuracy and computer time consumption. It was concluded that a linear interpolation of the displacements is the best alternative. In order to complete the list of calculations that have to be performed during a cycle the linear interpolation of $\underline{x}^{a}$ must be added to the updates of partition a:

$$
\underline{\mathrm{x}}_{\mathrm{n}+\alpha-\mathrm{j}}^{\mathrm{a}}=(\alpha-\mathrm{j}) \underline{\mathrm{x}}_{\mathrm{n}+\alpha}^{\mathrm{a}} / \alpha-\left(\mathrm{j} \underline{\mathrm{x}}_{\mathrm{n}}^{\mathrm{a}}\right) / \alpha, \text { for } \mathrm{j}=1,2, \ldots, \alpha-1
$$

This equation completes the subcycling algorithm. In fig. 1 a schematic overview of the computations is given.

\section{STABILITY}

The subcycling algorithm has been implemented in the PISCES-3DELK code for triangular constant strain membrane elements. A case study on the stability of the subcycling algorithm of a simple system (fig. 2) is performed. Node 1 is integrated with the time step $\Delta \mathrm{t}$ and node 2 with the time step $\alpha \Delta \mathrm{t}$. Only displacements in the plane of the drawing are considered. The equations of motion can - in case of linear material behaviour - be written in the form:

$$
\underline{\mathrm{M} \ddot{x}}+\underline{\mathrm{Kx}}=\underline{0}
$$

with $\underline{\mathrm{M}}$ the lumped mass matrix, $\underline{\mathrm{K}}$ the stiffness matrix and $\underline{x}^{\mathrm{T}}=\left[\mathrm{x}_{1 \mathrm{x}} \mathrm{x}_{1 \mathrm{y}} \mathrm{x}_{2 \mathrm{x}} \mathrm{x}_{2 \mathrm{y}}\right]$, where $x_{1 x}$ is the displacement of node 1 in $x$-direction etc. If the subcycling algorithm described in the previous section is applied to (20), the result can be written in the form:

$$
\underline{\mathrm{Ay}}^{\mathrm{n}+1}=\underline{\mathrm{By}}^{\mathrm{n}}
$$

with $\mathrm{y}^{\mathrm{n}}=\left[\mathrm{x}_{2 \mathrm{x}}^{\mathrm{n}+\alpha} \ldots \mathrm{x}_{2 \mathrm{x}}^{\mathrm{n}-\alpha+1}, \mathrm{x}_{2 \mathrm{y}}^{\mathrm{n}+\alpha} \ldots \mathrm{x}_{2 \mathrm{y}}^{\mathrm{n}-\alpha+1}, \mathrm{x}_{1 \mathrm{x}}^{\mathrm{n}+\alpha} \ldots \mathrm{x}_{1 \mathrm{x}}^{\mathrm{n}}, \mathrm{x}_{1 \mathrm{y}}^{\mathrm{n}+\alpha} \ldots \mathrm{x}_{1 \mathrm{y}}^{\mathrm{n}}\right]^{\mathrm{T}}$ and $\mathrm{A}$ and $\mathrm{B}$ are square matrices of dimension $6 \alpha+2$. Furthermore, $\underline{A}$ is a regular matrix. Eq. (21) can be rewritten in the form:

$$
\underline{\mathrm{y}}^{\mathrm{n}+1}=\underline{\mathrm{A}}^{-1} \underline{\mathrm{By}}^{\mathrm{n}}
$$

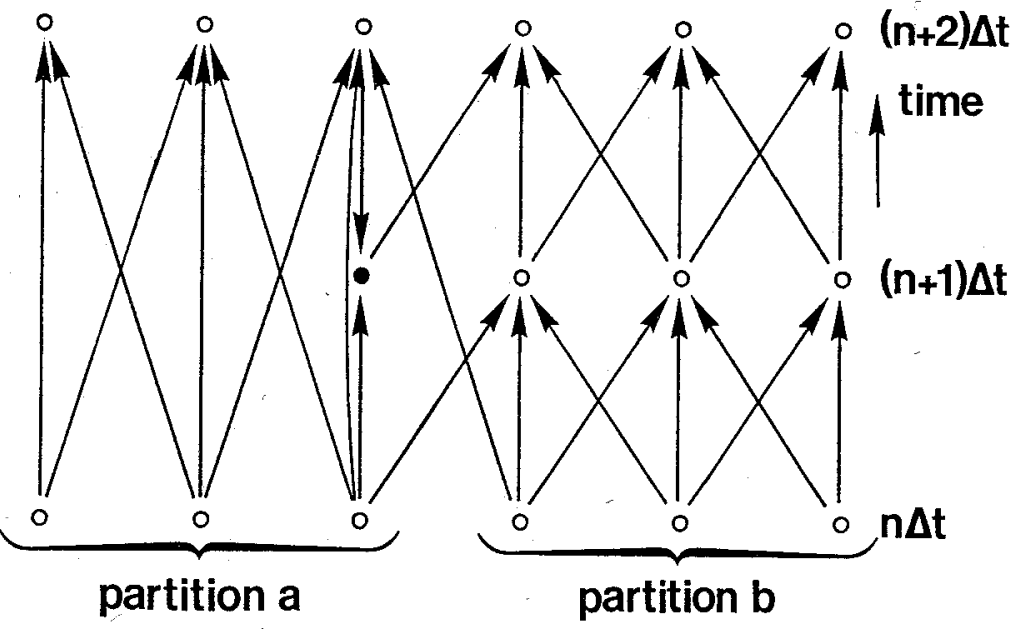

Fig. 1. A schematic overview of the computations.

Partition a is integrated with $2 \Delta t$ and partition b with $\Delta t$. A point represents a node at a certain time. An arrow pointing from one point to another indicates that the displacements and accelerations of the former point must be known to calculate these quantities of the latter point. For the calculation of the displacements of the bold point, only the displacements of the points from which the arrows start are necessary. The calculation of the velocities is not shown in this diagram.

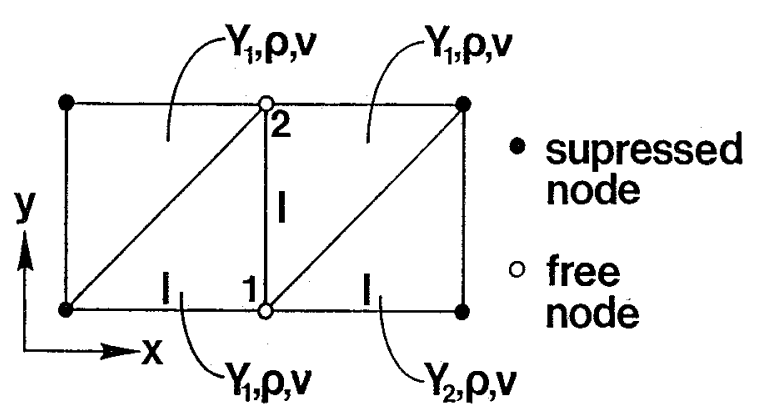

Fig. 2. The system for which the stability is derived.

Y: Youngs modulus, $\rho$ : density, $\nu$ : Poisson ratio, 1 : side length

- supressed node o free node

where $\underline{A}^{-1} \underline{B}$ is the so-called amplification matrix. The integration method is stable if the spectral radius $\rho_{S}$ of the amplification matrix $\underline{A}^{-1} \underline{B}$, defined by $\rho_{S}\left(\underline{A}^{-1} \underline{B}\right)=\max \left|\lambda_{i}\right|$ with $\lambda_{i}$ the ith eigenvalue of $\underline{A}^{-1} \underline{B}$, satisfies (Hughes, 1983): 


$$
\rho_{\mathrm{s}}\left(\underline{\mathrm{A}}^{-1} \underline{\mathrm{B}}\right) \leq 1
$$

The eigenvalues of the amplification matrix have been calculated numerically for different values of $\alpha$ and $\Delta$ t. Using the results of these calculations, the maximum stable time steps can be determined. In fig. 3, the maximum stable time steps are given as a function of $\alpha$. node1

Time step $[\mathrm{s}] * 10^{-5}$

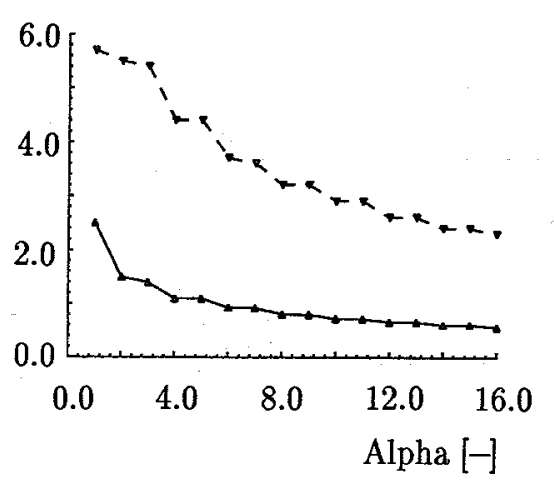

node 2

Time step $[\mathrm{s}] * 10^{-4}$

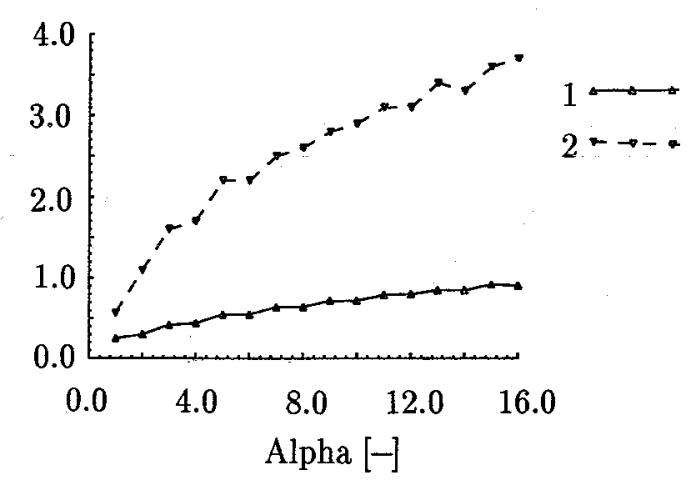

Fig. 3. The maximum stable time step as a function of the time step ratio. $\rho=10^{3}\left[\mathrm{~kg} \mathrm{~m}^{-3}\right], \nu=0.3[-], 1=0.1[\mathrm{~m}]$, thickness $=0.01[\mathrm{~m}]$

1: $\mathrm{Y}_{1}=10^{10}\left[\mathrm{Nm}^{-2}\right] \mathrm{Y}_{2}=10^{10}\left[\mathrm{Nm}^{-2}\right], 2: \mathrm{Y}_{1}=6.2510^{8}\left[\mathrm{Nm}^{-2}\right] \mathrm{Y}_{2}=10^{10}\left[\mathrm{Nm}^{-2}\right]$

It is concluded that the subcycling method is conditionally stable. The maximum stable time steps are larger than the time steps that follow from (5). This is due to the fact that (5) is determined for a free element. In the system of fig. 2, degrees of freedom have been suppressed. This changes the maximum frequency when compared to free elements.

\section{PARTITIONING OF ELEMENTS IN GROUPS}

For the description of the subcycle algorithm, only two different time steps were used. For calculations with the PISCES-3DELK code much more time steps are allowed, but they must satisfy the condition that all time steps are integer multiples of each other, although this condition is in general too severe. To start, for all elements the maximum stable time step is calculated. Then the elements are splitted up into groups. Group 1 contains elements with a time step satisfying $\Delta \mathrm{t}_{\min } \leq \Delta \mathrm{t}<2 \Delta \mathrm{t}_{\min }$, group 2 elements with $2 \Delta t_{\min } \leq \Delta \mathrm{t}<3 \Delta \mathrm{t}_{\min }$ etc., with $\Delta \mathrm{t}_{\min }$ the minimum time step of the mesh. Group 1 can be treated with the time step $\Delta \mathrm{t}_{\min }$, group 2 with $2 \Delta \mathrm{t}_{\min }$, group 3 with $3 \Delta \mathrm{t}_{\text {min }}$ etc. However, this group division does not satisfy the above condition. Therefore an algorithm has been developed that automatically finds that group division, satisfying the above condition, with minimal simulation costs. The user only has to specify whether subcycling must be applied. The algorithm finds the best group division and returns the expected computer time savings.

As mentioned before, the condition that all time steps have to be integer multiples of each other is too severe. Only the time steps of two neighbouring element groups have to be integer multiples of each other. But, because the difference in savings for the severe condition and the weak condition are small (about $2 \%$ ) and the fact that it is very difficult to check whether the weak condition is satisfied for a specific group division, it is chosen to satisfy the severe condition.

\section{TEST EXAMPLES}

The first test problem is the plate shown in fig. 4. The left side of the plate is clamped and the velocity of the right side of the plate is prescribed to be $0.1\left[\mathrm{~ms}^{-1}\right]$. In this figure also the time steps used are given. Nodes on the boundary lines are integrated with the largest time step of the groups the line separates. The displacement histories of some nodes - indicated in fig. 4 - are given for a calculation with and without subcycling in fig. 5 .

The generation algorithm predicted a computer time saving of $53 \%$. The actual saving was $44 \%$. The difference between the predicted and the achieved saving is caused by the fact that the generation algorithm does not take into account the overhead costs of subcycling and the fact that the algorithm presumes that the updates of the internal forces consume much more computer time than the updates of the nodes. In case of the relatively simple membrane elements this is not true. 


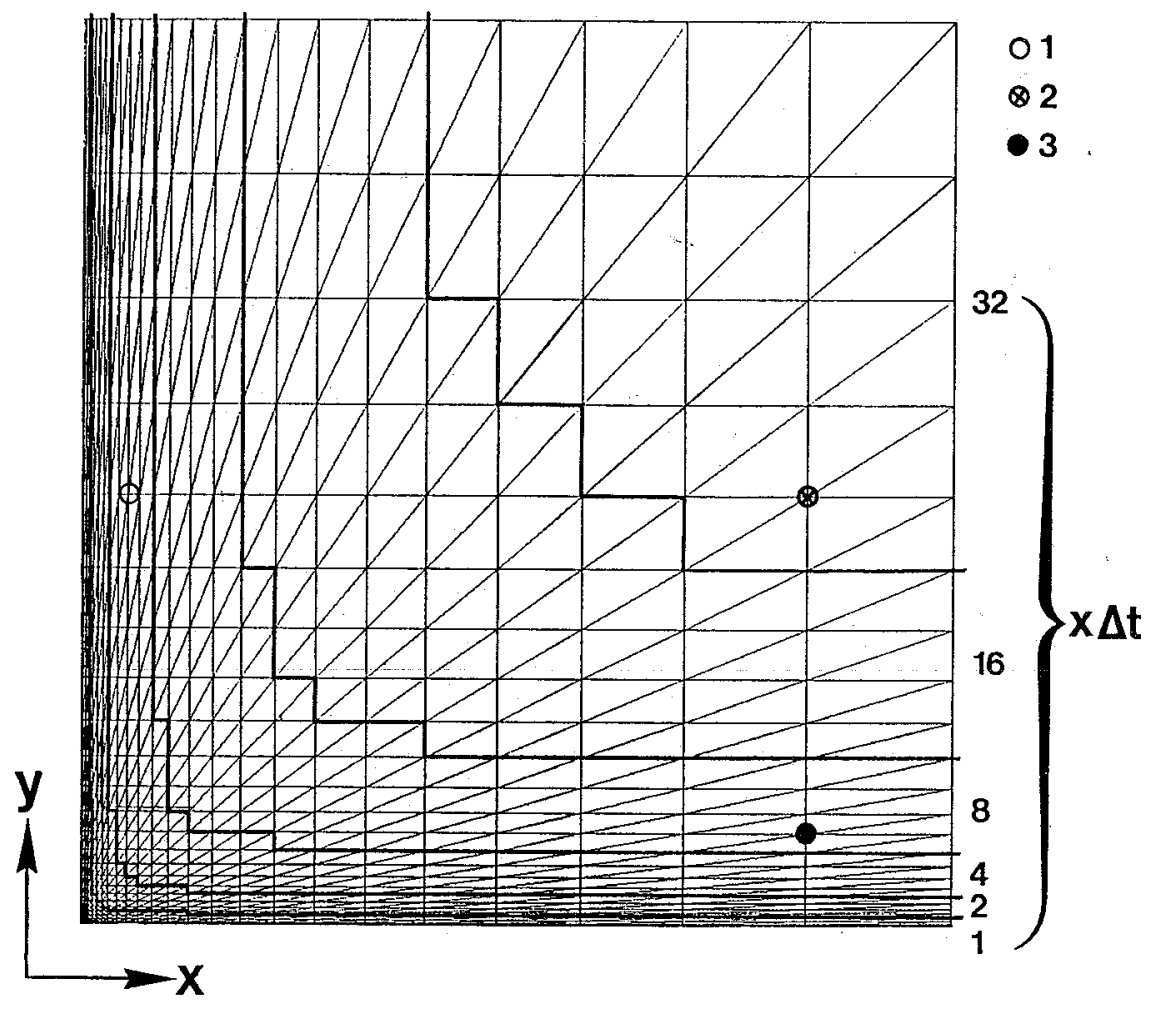

Fig. 4. The mesh for the calculation with the plate.

$\mathrm{Y}=3.0610^{8}\left[\mathrm{Nm}^{-2}\right], \rho=691.617\left[\mathrm{~kg} \mathrm{~m}^{-3}\right], \nu=0.3[\mathrm{H}$, Thickness $=0.0005[\mathrm{~m}]$, length $=10[\mathrm{~m}]$, width $=10[\mathrm{~m}]$.

The second test problem is the cylinder shown in fig. 6 . This problem has been chosen in order to check whether the use of different time steps would not yield displacements of the centre of gravity of the cylinder. For this reason, no kinematic boundary conditions were specified. The cylinder is loaded with a jump in the internal pressure of $6000\left[\mathrm{Nm}^{-2}\right]$ at time zero. Four different time steps were used (fig. 6).

The displacements of the centre of mass in y-direction varied between 0 and $2410^{-6}[\mathrm{~m}]$ for the calculation with subcycling and between 0 and $2110^{-6}[\mathrm{~m}]$ for the calculation without subcycling.

In fig. 7 , the displacement histories of two nodes are given for a calculation with and without subcycling. No significant differences are found.
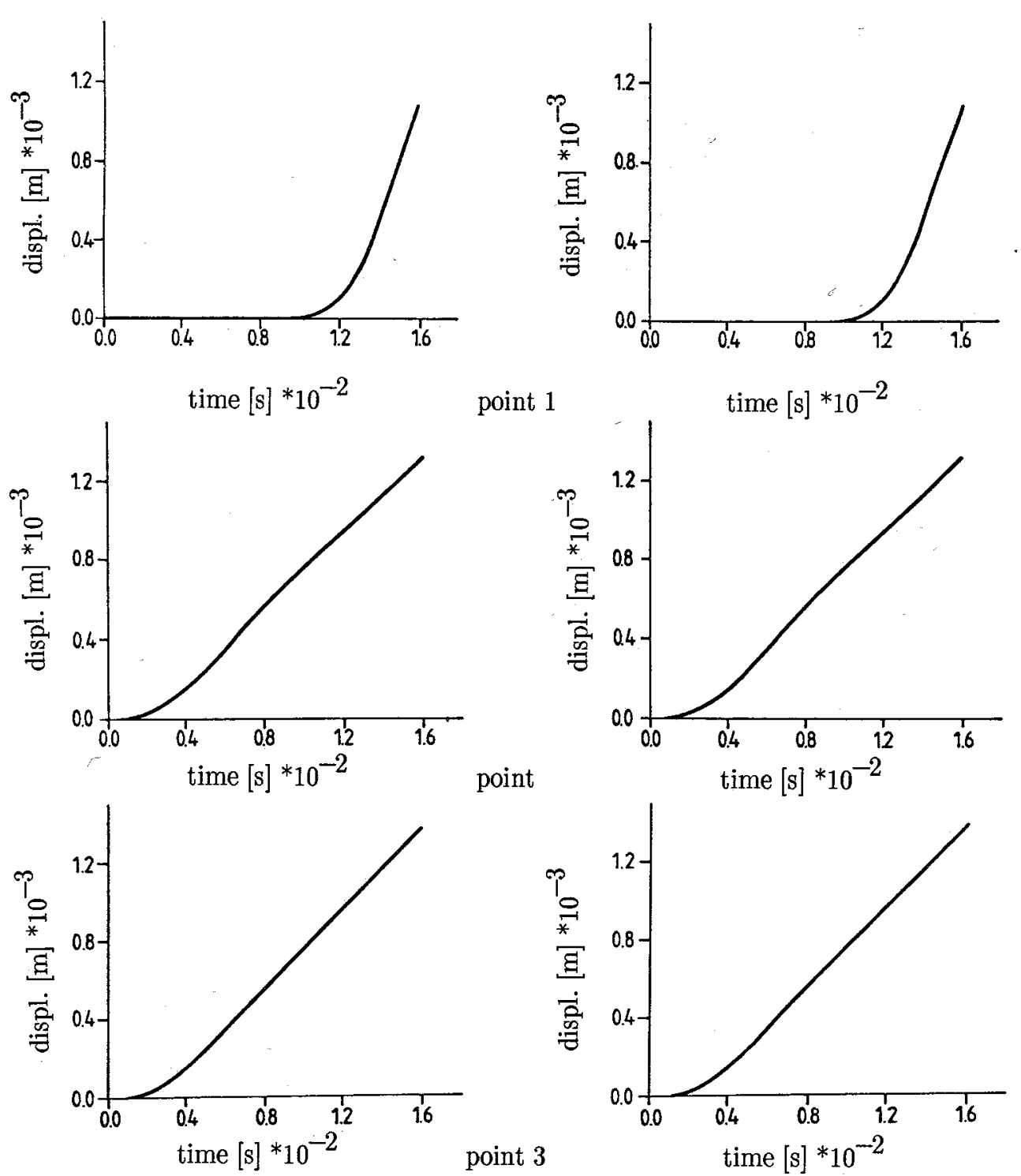

Fig. 5. Displacements histories for the plate. The left column is the result of a calculation with subcycling, the right column of a calculation without subcycling.

The predicted saving was $52 \%$. The achieved saving was only $35 \%$. This is larger than the difference in predicted and achieved savings for the plate. This difference is caused by the two reasons mentioned for the plate and the fact that the calculation of the external forces is not subcycled. 

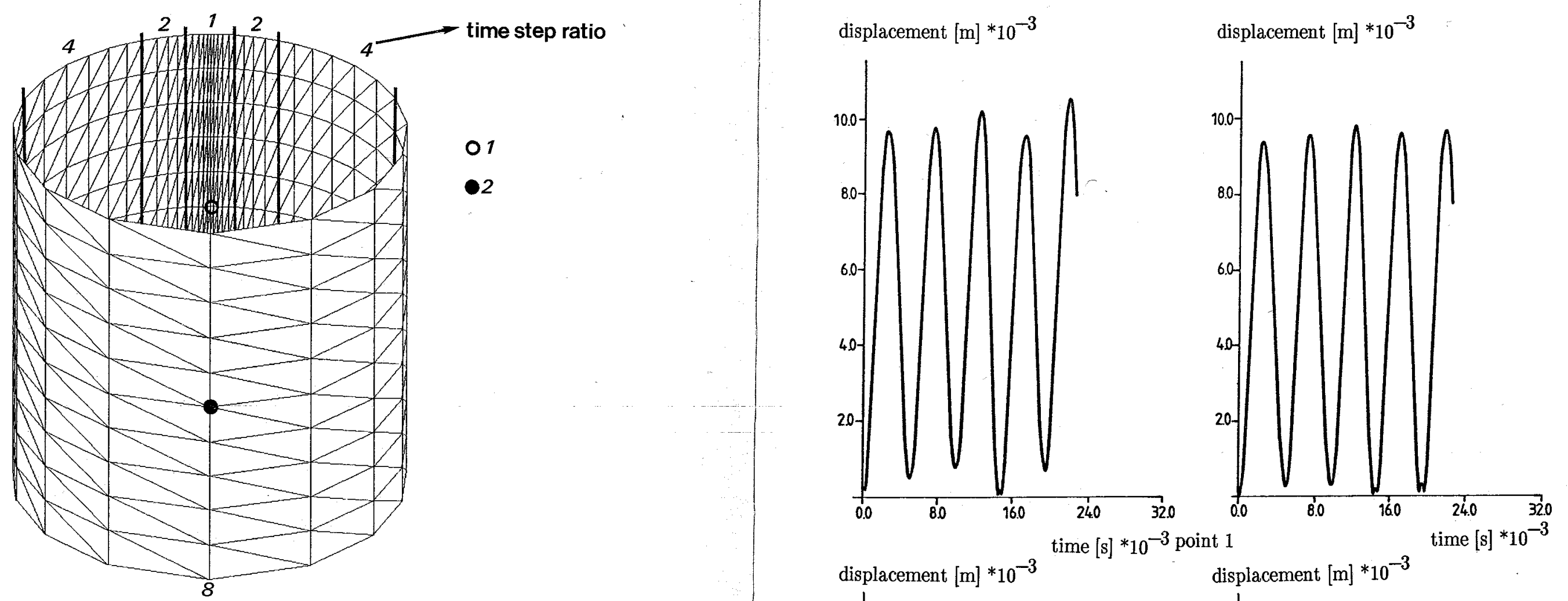

Fig. 6. The mesh for the calculation with the cylinder.

$\mathrm{Y}=3.0610^{8}\left[\mathrm{Nm}^{-2}\right], \rho=691.617\left[\mathrm{~kg} \mathrm{~m}^{-3}\right], \nu=0.3[-]$, Thickness $=0.001[\mathrm{~m}]$, Diameter $=1[\mathrm{~m}]$, Length $=1[\mathrm{~m}]$

\section{CONCLUSION AND FINAL REMARKS}

Subcycling indeed yields substantial computer time savings. The loss of accuracy is acceptable for many engineering applications.

In the future, the algorithm will be adjusted in order to allow impact between different meshes.
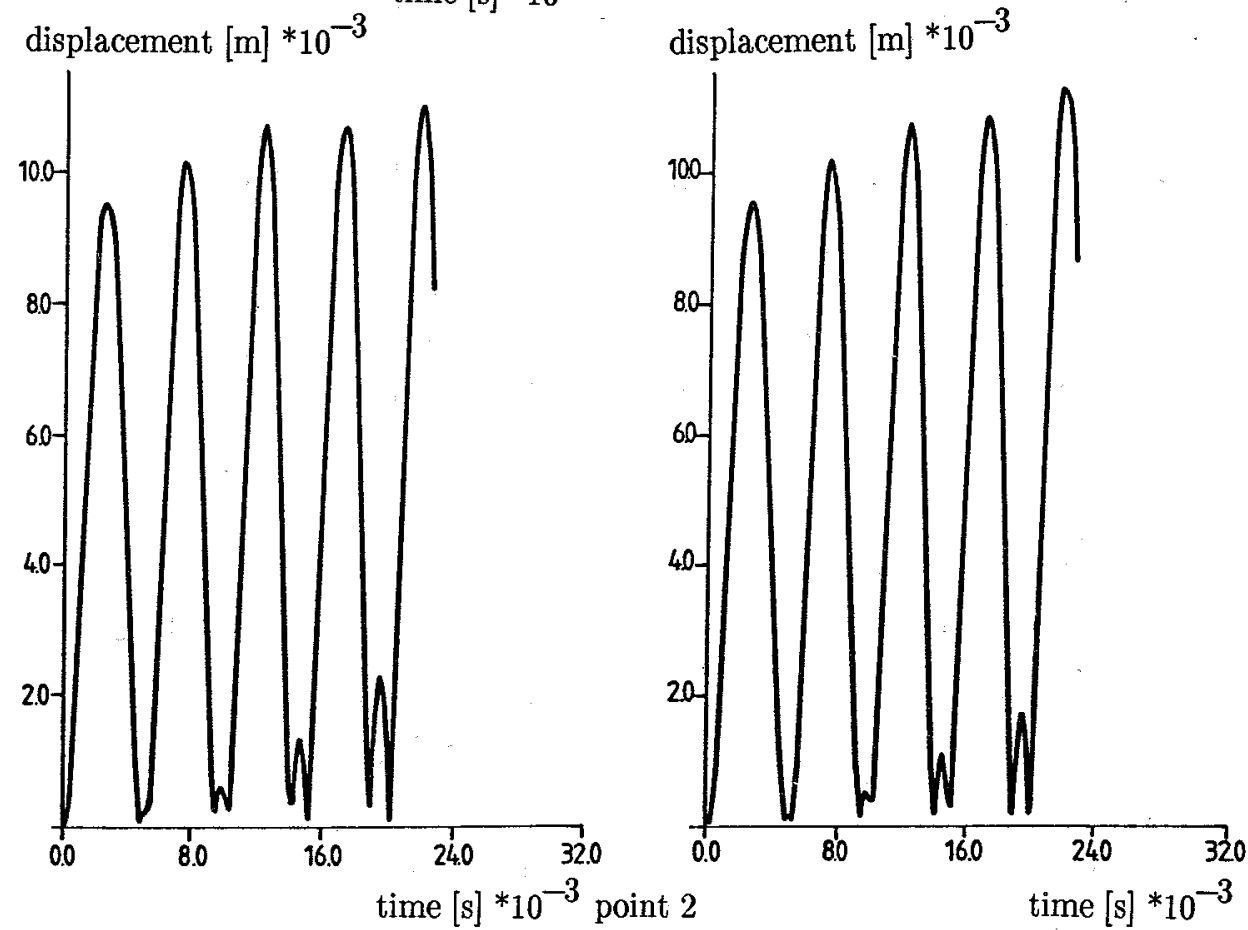

Fig. 7. Displacements histories for the cylinder. The left column is the result of a calculation with subcycling, the right column of a calculation without subcycling 


\section{ACKNOWLEDGEMENTS}

This work is partly sponsored by the Netherlands Organization for Applied Scientific Research - TNO

\section{REFERENCES}

Bruijs, W.E.M., Brekelmans, W.A.M., van Campen, D.H., de Coo, P.J.A., van der Heijden, A.M.A. \& Janssen, J.D.: Computer Time Reduction by Subcycling with an Application to Numerical Crash Analysis. In: Supercomputer Applications in Automotive Research and Engineering Development (C. Marino, ed.). pp. 347-371. Minneapolis, Minnesota: Cray Research, Inc. 1988

Courant, R., Friedriechs, K. \& Lewy, H.: On the Partial Differential Equations of Mathematical Physics. Math. Ann. 100, 32-74 (1928)

Hughes, T.J.R.: Analysis of Transient Algorithms with Particular Reference to Stability Behaviour. In: Computational Methods for Transient Analysis (T. Belytschko \& T.J.R. Hughes, eds.). pp. 67-155. North Holland 1983

Krieg, R.D. \& Key S.W.: Transient Shell Response by Numerical Time Integration. International Journal of Numerical Methods in Engineering. 7, 273-286 (1973)

\section{PART 3}

\section{ADVANCED DAE APPLICATIONS}

